\title{
Talent Management of Academics: Balancing Job Demands and Job Resources
}

\author{
Nicolene Barkhuizen
}

Department of Industrial Psychology, North-West University, Mmabatho, South Africa nicolene.barkhuizen@nwu.ac.za

Estee Roodt

Department of Human Resource Management, University of Pretoria, Pretoria, 2000

Nico Schutte

Department of Industrial Psychology, North-West University, Mmabatho, South Africa, 2745

\section{Doi:10.5901/mjss.2014.v5n20p2033}

\begin{abstract}
Talent management of academics is becoming a central management challenge as it becomes more difficult to retain key and competent staff. The main objective of this research was to determine the job demands and job resources of academic staff $(\mathrm{N}=146)$ that can have an impact on their talent management in South African higher education institutions. The results showed that academics experienced high job demands compared to the availability of job resources. The results also showed that white ethnic groups, associate professors, older academics and academics working for longer hours a week experienced significant higher job demands than their counterparts. Recommendations are made.
\end{abstract}

Keywords: Talent Management, academic staff, job demands, job resources, demographics

\section{Introduction}

Higher education institutions (HEls) have a significant role to play in a nation's wealth by fostering intellectual capital, economic growth, human development, and innovation in a 'knowledge intensive economy' (Ylojoki, 2013; Ylijoki \& Ursin, 2013). Moreover, a country's international competitiveness and growth of the knowledge community depends on its population having a strong and sustainable higher educational sector (Mapesela \& Hay, 2006; Van Heerden, Bohlmann, Giesecke, Makochekanwa and Roos, 2007).

However South African higher education institutions have been subjected to numerous changes over that past two decades. These changes have become prevalent through increases in student enrolment, increases in entrepreneurship, changes in funding and accountability, increased importance of performance-based incentives and increased emphasis on the efficiency of HE staff (Ntshoe, Higgs, Higgs \& Wolhuter, 2008). As a result the work of academics has become more emotionally demanding, fragmented and implies a loss of professional autonomy, scholar identity and psychological ownership (Bitzer, 2008; Ylojoki, 2013; Ylojoki \& Ursin, 2013).

Barkhuizen and Rothmann (2008) found that the job demands of academics staff can be attributed to a number of factors such as work overload, time constraints, lack of promotional opportunities, insufficient recognition, inadequate salaries, changing job roles, insufficient management, a lack of participation in management, inadequate job resources as well as inadequate funding, job insecurity, inequality in systems and a lack of regular feedback. Bezuidenhout and Cilliers (2010) further maintain that academics in South Africa are hard-pressed to increase their research output, manage larger classes as lecturers as well as supervise postgraduate students. A high physical workload is further aggravated by unclear roles and responsibilities. Although many academics would consider themselves to be essentially researchers, they are obligated to perform as lecturers as well, which results in numerous complications (De Bruin \& Taylor, 2005).

Accordingly, it appears that the job demands of academics have escalated, whilst the levels of support and other resources have declined. This in turn has a negative impact on the health and well-being of academics (Barkhuizen, Rothmann \& van de Vijver, 2013; Coetzee \& Rothmann, 2005; Mouton, 2010; Kinman, 2008; Pienaar \& Bester, 2008; Rothmann, Barkhuizen \& Tytherleigh, 2008). More seriously academic careers are becoming less attractive and HEls no longer preferred employers. Without well qualified and committed academic staff, no academic institution can ensure 
sustainability and quality over the long term (Pienaar \& Bester, 2008). Finding a highly qualified pool of talented scholars is thus limited and is becoming a central management challenge in the $21^{\text {st }}$ century.

Very few institutions can therefore afford their most valued and talented employees to leave when it is difficult to find better replacements (Netswera, Rankhumise \& Mavundla, 2005). Generally the academic profession appear not to be attractive for novice scholars. Several researchers found that younger academics experience higher levels of stress and burnout than their more seasoned counterparts (see Barkhuizen, 2005). Younger academics experience higher levels of job demands as a result of work politics, working conditions and job significance than older staff (Kinman \& Jones, 2003). High workload, coupled with greater responsibilities for duties related to work results in academics having to work long hours can be detrimental to academics' health and well-being. A study by Barkhuizen (2005) among South African HEls clearly pointed out that academics working for more than 50 hours a week experienced high levels of exhaustion as a result of increasing job demands. Other research found that academics employed on higher job levels such as associate professors tend to experience more role overload and job demands than junior lecturers (Barkhuizen, 2005; Winter, Taylor \& Sarros, 2000).

Against this background the main objective of this research was to explore the job demands and job resources as experienced by academics in South African higher education institutions. In addition this research also aimed to determine whether significant differences exist in the job demands and job resources of academic staff based on their demographic characteristics. For purposes of this research we adopt the job-demands-resources model to conceptualise job demands and resources in the academic work context (see Bakker \& Demerouti, 2008; Demerouti, Nachreiner, Bakker \& Schaufeli, 2001). Job demands refer to the physical, psychological, social or organisational aspects of the job that require continued physical or psychological effort and are consequently associated with physiological and/or psychological cost. Job resources in contrast are the physical, psycho-social or organisational elements that are necessary for an individual and consequently the organisation to reach their goals, reduce job demands, and encourage development. The relationship between the job-demands and job-resources has an immediate effect on the motivation and job performance of academics (Boyd, Bakker, Winefield, Gillespie \& Stough, 2011; Rothmann \& Jordaan, 2006).

In the light of the preceding background the following two research hypotheses are set:

Hypothesis 1: Academics experience a higher level of job demands in higher education institutions compared to existing job resources

Hypothesis 2: Significant differences exist in the job demands of academics based on their demographic characteristics

\section{Research Design}

\subsection{Research Method}

A quantitative research approach was followed in this study as the aim was to explore the job demands and job resources among academics in South African higher education institutions. A cross-sectional survey design was used to collect data and attain the research goals.

\subsection{Sample}

The sample of this research consisted of academics in South African Higher Education Institutions. From the 360 questionnaires that were sent out to the sample 158 completed questionnaires were received with only 146 usable for data analyses. This represents a response rate of $41 \%$. An equal number of male and female academics participated in this research (50\%). Most the respondents were aged between 40-49 years (33.8\%), white (44.4\%) and English speaking (37.1\%). The respondents were primarily appointed on lecturer level (41.1\%), in possession of a Masters Degree (41.1) and executing the functions of both researcher and lecturer (66.4\%). Most of the respondents were employed between 0 10 years in their current job (88.8\%) and institution (60.4\%) and work between 41 and 50 hours per week (38.6\%).

\subsection{Measuring Instruments}

The Job Characteristics Inventory (Barkhuizen, 2005) was used to measure the job demands and the job resources of the participants. The JCS consists of 41 items. The questions are rated on a four-point scale ranging from 1 (Never) to 4 (Always). The dimensions of the JCS include pace and amount of work, mental load, emotional load, work variety, opportunities to learn, work independence, relationships with colleagues, relationships with supervisors, ambiguities of 
work, information, communication, participation, contact possibilities, remuneration and career possibilities. Acceptable Cronbach Alpha Coefficients were obtained from the above scale in South African studies (Barkhuizen, 2005).

\subsection{Data Analyses}

Statistical analysis was carried out using the SPSS Program (SPSS, 2014). The reliability and validity of the Job Characteristics Inventory were determined by means of exploratory factor analysis and Cronbach alpha coefficients. Multivariate analysis of variance (MANOVA) was used to determine the significance of differences between the job demands and job resources of demographic groups. When an effect is significant in MANOVA, ANOVA was used to discover which dependent variables are affected. In terms of statistical significance, a value at a $95 \%$ confidence interval level $(p \leq 0,05)$ was set (Field, 2009). Cohen's $(1988, p .283)$ guidelines for the interpretation of effect sizes: 0.0099 constitutes a small effect, 0.0588 a medium effect and 0.1379 a large effect was used to interpret the magnitude of the effect sizes.

\section{Results}

Exploratory factor analysis using principal component analysis was done on the 45 items of the $\mathrm{JCl}$. The eigen values initially showed that nine factors can be extracted. However, closer inspection of the pattern matrix showed that the items loaded onto three factors. A Principal Component Analyses was conducted again using direct oblimin rotation to specify the three factors. Seven items were excluded from the analyses due to low and problematic factor loadings. The three factors were labelled Job Resources (Factor 1), Workload (Factor 2), and Remuneration (Factor 3). These three factors explain $46.207 \%$ of the variance. The pattern matrixes are reported in Table 1 below. The items showed acceptable loadings.

Table 1: Pattern Matrix for the Job Characteristics Inventory

\begin{tabular}{|c|c|c|c|c|c|c|c|}
\hline & \multicolumn{3}{|c|}{ Component } & & \multicolumn{3}{|c|}{ Component } \\
\hline & Job Resources & Job Demands & Remune & & Job Resources & Job Demands & Remune \\
\hline $\mathrm{JCl}$ & -.017 & .709 & -135 & $\mathrm{JCl} 23$ & .727 & -.122 & -.024 \\
\hline $\mathrm{JCl} 2$ & -.050 & .769 & -.098 & $\mathrm{JCl} 24$ & .735 & -166 & .015 \\
\hline $\mathrm{JCl} 4$ & -.014 & .771 & .096 & $\mathrm{JCl} 25$ & .608 & -.013 & .018 \\
\hline $\mathrm{JCl} 5$ & .078 & .575 & .046 & $\mathrm{JCl} 26$ & .482 & -.125 & -.112 \\
\hline $\mathrm{JCl} 6$ & .074 & .737 & -.034 & $\mathrm{JCl} 27$ & .724 & .066 & -.055 \\
\hline $\mathrm{JCl} 7$ & -.010 & .717 & .009 & $\mathrm{JCl} 28$ & .743 & -.029 & -.018 \\
\hline $\mathrm{JCl} 8$ & .014 & .455 & -.054 & $\mathrm{JCl} 29$ & .678 & .103 & .017 \\
\hline $\mathrm{JCl9}$ & -.185 & .632 & -.051 & $\mathrm{JCl} 30$ & .659 & .186 & .035 \\
\hline JCl12 & .493 & .260 & .106 & $\mathrm{JCl} 31$ & .608 & .116 & .040 \\
\hline $\mathrm{JCl13}$ & .466 & .100 & .287 & $\mathrm{JCl} 32$ & .655 & .076 & .130 \\
\hline JCl14 & .466 & .119 & .256 & $\mathrm{JCl} 33$ & .597 & .033 & .139 \\
\hline $\mathrm{JCl15}$ & .656 & .078 & .083 & $\mathrm{JCl} 34$ & .740 & -.051 & .040 \\
\hline $\mathrm{JCl} 16$ & .673 & .004 & -.255 & $\mathrm{JCl} 35$ & .813 & .039 & -.053 \\
\hline JCl17 & .626 & -.033 & -.225 & $\mathrm{JCl} 36$ & .529 & .192 & .110 \\
\hline $\mathrm{JCl18}$ & .641 & -.087 & -.213 & $\mathrm{JCl} 37$ & .367 & .114 & .221 \\
\hline $\mathrm{JCl19}$ & .577 & -.201 & .127 & $\mathrm{JCl} 40$ & -.022 & -101 & .803 \\
\hline $\mathrm{JCl} 20$ & .498 & -.232 & .117 & $\mathrm{JCl} 41$ & -.094 & .027 & .836 \\
\hline $\mathrm{JCl} 21$ & .549 & -.175 & -.051 & $\mathrm{JCl} 42$ & .093 & -.137 & .827 \\
\hline $\mathrm{JCl} 22$ & .655 & -.223 & .049 & $\mathrm{JCl} 43$ & .038 & -.104 & .722 \\
\hline
\end{tabular}

A second order factor analysis was performed using the principal component analysis extraction method on the three factors identified in the primary factor analysis. The purpose of this analysis was to specify the job demands and job resources more clearly. Job Resources and remuneration loaded onto one factor and job Demands on the second factor. The first factor was labelled Job Resources and the second factor Job Demands. The two factors explained $75.219 \%$ of the variance. The descriptive statistics and reliabilities of the job demands and job resources are reported in Table 2 below. 
Table 2: Descriptive statistics of the Job Characteristics Inventory

\begin{tabular}{|l|c|c|c|c|c|}
\hline & Mean & SD & Skewness & Kurtosis & Cronbach Alpha \\
\hline Job Demands & 3.0621 & .53659 & -.200 & -.801 & .833 \\
\hline Job Resources & 2.9320 & .47902 & -.367 & -.172 & .930 \\
\hline
\end{tabular}

The results in Table 2 show very good to excellent reliabilities for the job demands and job resources scales. The results further show that academics in this sample experienced a high level of job demands. The job demands were also slightly higher than the job resources. The above results confirm Hypothesis 1 namely that academic staff experience high job demands.

Next the Manova tests were done to investigate whether there are any significant differences between the job demands and job resources of academics based on their demographic characteristics. The results are reported in Table 3 below.

Table 3: Manova: Job Demands, Job Resources and Demographic variables

\begin{tabular}{|l|c|c|c|c|c|c|}
\hline Biographical Variable & Wilks' Lambda Value & $\boldsymbol{F}$ & Hypothesis df & Error df & Sig. & Partial Eta Squared \\
\hline Gender & .975 & $1.828^{\mathrm{b}}$ & 2.000 & 141.000 & .165 & .025 \\
\hline Ethnicity & .913 & $2.117^{\mathrm{b}}$ & 6.000 & 274.000 & .052 & .044 \\
\hline Home Language & .871 & $4.957^{\mathrm{b}}$ & 4.000 & 278.000 & .001 & .067 \\
\hline Age & .886 & $2.129^{\mathrm{b}}$ & 8.000 & 272.000 & .033 & .059 \\
\hline Qualifications & .931 & $1.719^{\mathrm{b}}$ & 6.000 & 282.000 & .117 & .035 \\
\hline Job Level & .872 & $2.480^{\mathrm{b}}$ & 8.000 & 280.000 & .013 & .066 \\
\hline Job Category & .984 & $.562^{\mathrm{b}}$ & 4.000 & 278.000 & .691 & .008 \\
\hline Years Service & .928 & $1.838^{\mathrm{b}}$ & 6.000 & 288.000 & .092 & .037 \\
\hline Years Job & .981 & $.660^{\mathrm{b}}$ & 4.000 & 278.000 & .620 & .009 \\
\hline Hours Work & .824 & $2.801^{\mathrm{b}}$ & 10.000 & 276.000 & .003 & .092 \\
\hline
\end{tabular}

The results in Table 3 show that significant differences exist in the job demands experienced by academics based on their demographic characteristics such as ethnicity, home language, age, job level and number of hours work in a week. The results are briefly discussed below.

- The Wilks' Lambda for ethnicity is equal to $0.913[F(6,274)=2.117, p \leq 0.05]$. Analysis of each dependent variable, using a Bonferroni adjusted alpha level of 0,025 , showed that the respondents differ in terms of Job Demands $\left(F_{(3,143)}=4.067, p \leq 0,05\right.$, partial $\left.\eta^{2}=0,081\right)$. The results showed that the white ethnic group experienced higher job demands than the black ethnic group. The effect was medium.

- The Wilks' Lambda for home language is equal to $0.871[F(4,278)=4.957, p \leq 0.05]$. Analysis of each dependent variable, using a Bonferroni adjusted alpha level of 0,025 , showed that the respondents differ in terms of Job Demands $\left(F_{(4,142)}=9.291, p \leq 0,05\right.$, partial $\left.\eta^{2}=0,117\right)$. According to the results respondents speaking either Afrikaans or English experience higher job demands then respondents speaking indigenous languages. The effect was medium.

- The Wilks' Lambda for age is equal to $0.886[F(8,272)=2.129, p \leq 0.05]$. Analysis of each dependent variable, using a Bonferroni adjusted alpha level of 0,025 , showed that the respondents differ in terms of Job Demands $\left(F_{(4,142)}=9.291, p \leq 0,05\right.$, partial $\left.\eta^{2}=0,097\right)$. Academics aged between 50 to 59 years of age experienced a higher level of job demands than the academics aged between 20 to 29 years of age. The effect was medium.

- The Wilks' Lambda for job level is equal to $0.872[F(8,280)=2.480, p \leq 0.05]$. Analysis of each dependent variable, using a Bonferroni adjusted alpha level of 0,025 , showed that the respondents differ in terms of Job Demands $\left(F_{(4,142)}=3.401, p \leq 0,05\right.$, partial $\left.\eta^{2}=0,088\right)$. According to these results associate professors experienced higher job demands that junior lecturers. The effect was medium.

- The Wilks' Lambda for hours of work is equal to $0.824[F(10,276)=2.801, p \leq 0.05]$. Analysis of each dependent variable, using a Bonferroni adjusted alpha level of 0,025 , showed that the respondents differ in terms of Job Demands $\left(F_{(5,141)}=4.062, p \leq 0,05\right.$, partial $\left.\eta^{2}=0,127\right)$. Academics working for more than 40 hours a work week experienced more demands than academics working for less than 20 hours in a week. The effect was medium. 
The above results partially confirm hypothesis 2 , namely that significant differences exist between the job demands of academic staff based on their demographic characteristics.

\section{Discussion}

Talent management of academic staff is becoming a serious management challenges as it becomes more difficult to attract and retain quality staff members. The main objective of this research was to explore the job demands and job resources experienced by academic staff members in South African higher education institutions. In addition this research also aimed at determining whether significant differences exist between the job demands and resources of academics based on their demographic characteristics.

The results of this research confirmed the previous findings that academic staff members are still experiencing high job demands in relation to the available job resources (see Barkhuizen, 2005; Barkhuizen \& Rothmann, 2008; Bezuidenhout \& Cilliers, 2010). The results further showed that significant differences exist between the job demands experienced by academics based on their demographic characteristics. In this research high job demands were mostly experienced by older academics employed on higher job ranks. One possible explanation for these findings are related to the fact that HEls are struggling to attract younger academics to vacant positions and therefore older and more seasoned researcher are faced with escalating workloads (see Pienaar \& Bester, 2008). Another possible explanation can be attributed to the fact that higher education institutions are operating in a rapid changing work environment (see Ntshoe et al., 2008). Older academics are not necessarily prepared for all these changes and may experience a loss of scholar identity which in turn can result in their jobs becoming more demanding (see Bitzer, 2008; Ylojoki, 2013). The results are in line with Barkhuizen (2005) and Winter et al. (2000) who found that associate professors are more prone to higher workloads compared to younger academics. The results however are in contrast with the findings of Kinman and Jones (2003) who suggest that younger academics experience more job demands than their older counterparts.

Not surprising this research also showed that academics working for longer hours in a week experience higher job demands compared to those working fewer hours in a week (see Barkhuizen, 2005). The results also showed that the white ethnic group, speaking Afrikaans and Englosh experience higher job demands compared to black ethnic groups speaking indigenous languages. This a new finding and more research is needed to clarify these results.

This research had some limitations. The sample included academic staff members of South African higher education institutions. As a result the findings of this research cannot be generalised to other organisations. This research also used a cross-sectional research design was used which limits the research in terms of cause and effect inferences that can be made in terms of talent management practices in local government.

In conclusion this research highlighted the current state of the academic work environment in South African higher education institutions. The results clearly pointed out that job demands are still prevalent for academics without the availability of proper job resources. The present academic environment has serious implications for the effective talent management of academic staff with specific reference to attracting younger academics whilst at the same time retaining a skilled and competent academic workforce. Higher education management should therefore take stock of the current talent management practices and develop appropriate interventions to alleviate incidences of high demands and improve job resources. The future of higher education and South Africa as a developing country depends on a skills academic workforce. Therefore we cannot afford to lose academic staff as result of poor talent and human resource management practices in higher education institutions.

\section{References}

Bakker, A.B., \& Demerouti, E. (2008).Towards a model of work engagement. Career Development International, 13, 3, $209-223$.

Barkhuizen, E. N. (2005). Work wellness of academic staff in higher education institutions. Unpublished Doctoral Thesis, Northwest University.

Barkhuizen, E. N., \& Rothmann, S. (2008). Occupational stress of academics in South African higher education institutions, South African Journal of Psychology, 28, 2, 321-336.

Barkhuizen, E.N., Rothmann, S. \& van de Fijver, F. (2013). Burnout and engagement of academics in higher education institutions: Effects of Dispositional Optimism. Stress \& Health. 2013 Aug 16. doi: 10.1002/smi.2520. [Epub ahead of print].

Bezuidenhout, E., \& Cilliers, F.V.N. (2010). Burnout, work engagement and sense of coherence in female academics in higher education in South Africa. SA Journal of Industrial Psychology, 36, 1, 1-11.

Bitzer, E.M. (2008). The Professoriate in South Africa: Potentially risking status inflation. South African Journal of Higher Education, 22, 2, 265-281.

Boyd, C.M., Bakker, A.B., Pignata, S., Winefield, A.H., Gillespie, N. et al. (2011). A longitundal test of the Job Demands-Resources 
model among Australian University Academics. Applied Psychology: An International Review, 60, 1, 112-140.

Coetzee, S.E. \& Rothmann, S. (2005). 'Occupational stress, organisational commitment and ill health of employees at a higher education institution in South Africa', South African Journal of Industrial Psychology, 31, 1, 47-54.

Cohen, J. (1988). Statistical power analysis for the behavioral sciences (Revised ed.). Orlando, FL: Academic Press.

De Bruin, G.P., \& Taylor, N. (2005). Development of the sources of work stress. South African Journal of Psychology, 35, 4, 748-765.

Demerouti, E., Bakker, A. B., Nachreiner, F., \& Schaufeli, W. B. (2001). The job demands-resources model of burnout. Journal of Applied Psychology, 86, 499-512.

Field, A. (2009). Discovering statistics using SPSS (3rd Ed). London: Sage.

Kinman, G. (2008). Work stressors, health and sense of coherence in UK academic employees. Educational Psychology: An International Journal of Experimental Educational Psychology, 28, 7, 823-835.

Kinman, G., \& Jones, F. (2003). Running up and down the escalator: Stressors and strains in UK academics. Quality in Higher Education, 9, 21-38.

Mapesela, M. \& Hay, D.H.R. (2006). The effect of change and transformation on academic staff and job satisfaction: A case of a South African University. Higher Education, 52, 711-747.

Mouton, J. (2010). African experience with collaborative graduate programmes. Research report, Stellenbosch: University of Stellenbosch.

Netswera, F. G., Rankhumise, E.M. \& Mavundla, T. R. (2005). Employee retention factors for South African higher education institutions: A case study. SA Journal of Human Resource Management, 3, 2, 36-40.

Ntshoe, I., Higgs, P., Higgs, L.G., \& Wolhuter, C.C. (2008). The changing academic profession in higher education and new managerialism and corporatism in South Africa. South African Journal of Higher Education, 22, 2, 391-403.

Pienaar, C. \& Bester, C. L. (2008). The retention of academics in the early career phase: Empirical research. SA Journal of Human Resource Management, 6, 2, 32-41

Rothmann, S., Barkhuizen, N. \& Tytherleigh, M. 2008. A model of work-related health for academic staff in South African higher education institutions. South African Journal of Higher Education, 22, 2, 404-422.

Rothmann, S., \& Jordaan, G.M.E. (2006). Job demands, job resources and work engagement of academic staff in South African higher education institutions. South African Journal of Industrial Psychology, 32, 4, 87-96.

SPSS Inc. (2014). SPSS 22 for Windows. Chicago, IL: Author.

Van Heerden, J.H., Bohlmann, H.R., Giesecke, J.A., Makochekanwa, A., Roos, E.L. (2007). Higher Education Impact: Universities in the South African Economy. Higher Education South Africa, Pretoria.

Winter, R., Taylor, T., \& Sarros, J. (2000). Trouble at mill: Quality of academic work life issues within a comprehensive Australian university. Studies in Higher Education, 25, 279-294.

Ylijoki, O.H. \& Ursin, J. (2013). The construction of academic identity in the changes of Finnish higher education. Journal for Studies in Higher Education, 14, 5, 495-506.

Ylijoki, O.,H. (2013). Boundary-work between work and life in the/ high-speed university. Studies in Higher Education, 38, 2, $242-255$. 